discurso (30), 1999: 131-58

\title{
Dúvidas, Certezas e Linguagem: o Argumento do Sonho*
}

\author{
Arley R. Moreno**
}

Resumo: Este artigo aplica o estilo da terapêutica wittgensteiniana ao argumento do sonho em sua versão cartesiana. Além disso, ele sugere algumas linhas de comparação entre o projeto husserliano de constituição e a terapêutica wittgensteiniana.

Palavras-chave: ceticismo - dogmatismo - fenomenologia - terapia - linguagem

\section{I}

A figura do Cogito cartesiano assim como o processo da dúvida hiperbólica que conduz até ele são, filosoficamente, atuais e fecundos porque permitem-nos ainda criticá-los e desenvolvê-los por meio da explicitação de seus pressupostos.

É assim, por exemplo, que Husserl, apesar de reconhecer a importância filosófica do Cogito ao introduzir a dimensão transcendental do sujeito,

* Este texto foi apresentado durante o seminário O Legado de Wittgenstein, realizado pelo Programa de Pós-Graduação em Filosofia e Metodologia das Ciências da UFSCar; foi também apresentado durante a instalação do seminário Wittgenstein - Filosofia da Linguagem e do Conhecimento, promovido pelo Centro de Estudos em Filosofia Moderna e Contemporânea (Cemodecon), Departamento de Filosofia, IFCH, Unicamp.

** Professor do Departamento de Filosofia do IFCH, Unicamp. 
dirige severas críticas às limitações que o próprio Descartes the impôs (Husserl 6, p. 60-82). Uma vez conquistado o Cogito, Descartes teria condições, segundo Husserl, de desenvolver e explorar uma concepção de subjetividade autônoma, independente de qualquer transcendência e, portanto, capaz de constituir por si própria o sentido da objetividade. Todavia, segundo Husserl, Descartes, herdeiro do paradigma da mecânica galileana, impediu-se de dar o passo em direção a uma "imanência transcendental", i.e., à autonomia da função transcendental recém-conquistada pelo sujeito, tornando-o dependente de um princípio de ordem superior e transcendente, este sim, garantia da objetividade. O Cogito cartesiano, embora sendo uma figura da subjetividade não-empírica, perde-se em suas próprias fantasias, pois a "realidade formal" de suas representações vai depender diretamente da função constitutiva de um Deus, princípio de realidade. Sem esta garantia transcendente, o Cogito é meramente um conjunto de processos naturais, matéria para uma psicologia, retornando, assim, sobre seus próprios passos.

Consolida-se, pois, filosoficamente, a separação galileana entre o mundo exterior, escrito em caracteres matemáticos e por isso mesmo inteligível, e seu complemento interior, o mundo das representações subjetivas, uma espécie de subproduto do mundo inteligível. A realidade formal das representações do sujeito cartesiano, garantia da inteligibilidade e proteção contra suas fantasias, escapa a esse sujeito e torna-se dependente do princípio absoluto de realidade que é Deus. Fica, assim, filosoficamente justificada a separação entre as representações da objetividade e a objetividade de seus conteúdos. Em outros termos, o acesso aos caracteres matemáticos, que tornam inteligível a objetividade exterior, passa necessariamente pela intermediação de um Deus, garantia da autonomia desta objetividade relativamente às fantasias do sujeito. É que, como diz, justamente, Husserl, Descartes inaugura apenas o "início do começo" da filosofia transcendental, fazendo, em seguida, retroceder o sujeito sobre o mesmo passo que havia dado.

Eis uma crítica filosoficamente profunda, a partir da qual Husserl desenvolve sua própria concepção de subjetividade enquanto imanência transcendental e, assim, seu projeto de descrição das formas de constituição do 
sentido da objetividade. Uma tal crítica revela, por outro lado, a fecundidade e atualidade do Cogito cartesiano e de seu processo de construção por meio do princípio de razão suficiente aplicado sob a forma da dúvida hiperbólica. Note-se que é exatamente este processo de raciocínio, aplicado por Descartes, o que permite a apresentação de um sujeito não-empírico e modelo da função transcendental - embora, como vimos, incapaz ainda de exercê-la.

De fato, o Cogito não é conquistado por meio de uma qualquer intuição ou introspecção, mas, pelo contrário, exclusivamente pela aplicação de um operador formal, a dupla negação, encarnado no argumento da reiteração da dúvida aplicada a si própria: não posso duvidar que duvido sob o risco de gerar uma contradição. É este pensar, livre de quaisquer amarras empíricas, que marca uma posição teórica enquanto conceito virtualmente gerador e constitutivo dos sentidos dos objetos em geral. Ao produzir este argumento, que corresponde a uma operação formal, Descartes está situando a dúvida no nível mais elementar de constituição do sentido, a saber, naquele nível em que a aplicação incorreta de um conceito gera, necessariamente, uma contradição para o pensamento. Se conhecemos a significação do conceito e, portanto, soubermos aplicá-lo corretamente, a conclusão imporse-á com necessidade, e a contradição será evitada. Eis o modelo de evidência, clareza e distinção, almejado por Descartes - aliás, e mais uma vez, conforme o paradigma da mecânica galileana! Situação, pois, paradoxal, tendo em vista a crítica husserliana: é o mesmo paradigma de inteligibilidade que impede Descartes de explorar a função transcendental do sujeito que lhe permite, também, conquistar o modelo da subjetividade transcendental.

Deste último ponto de vista, a conquista do modelo transcendental está fundada naquele nível elementar de constituição do sentido, nível em que não é logicamente possível negar a aplicação correta de um conceito conhecido, nem mesmo em sonho e até contra as galhofeiras investidas de um gênio espertalhão. A evidência, clara e distinta, da idéia assim conquistada, i.e., o sujeito pensante, repousa sobre o conhecimento das regras elementares do sentido, afastando este sujeito das contingências empíricas que envolvem seu pensamento. E chegamos, aqui, às margens de um outro pro- 
jeto filosófico de descrição das condições constitutivas do sentido da objetividade: a descrição wittgensteiniana dos usos das palavras. As observações que se seguem procuram situar o Cogito cartesiano relativamente aos pressupostos lingüísticos sobre os quais se baseia e que não foram, nem poderiam ter sido, explicitados por Descartes. Ao fazê-lo, veremos sua fecundidade e atualidade, assim como suas limitações, mas, agora, sob outro prisma, i.e., do ponto de vista de uma pragmática filosófica inspirada na descrição wittgensteiniana dos usos das palavras.

\section{II}

Posso saber que estou sonhando? Sim, se estiver consciente de meu estado mental!

Ao sonhar que chove, sonho com a referência da palavra "chuva", assim como ao ver a chuva, desperto, percebo a referência da palavra "chuva". Sonhamos com as mesmas referências que atribuímos às palavras quando despertos, assim como, despertos, pensamos e percebemos as mesmas referências que atribuímos em sonho às imagens oníricas. Da mesma maneira, nos respectivos relatos: são mesmas as referências, quando sonho, que, desperto, atribuo às palavras usadas para descrever estados de coisas sonhados, e, também, as mesmas quando desperto, que, sonhando, atribuo às palavras para descrever estados de coisas que percebo acreditando estar desperto.

Eis uma situação em que são mesmas as referências das palavras e descrições a respeito do que pensamos, percebemos e dizemos quando despertos e em sonho. Ora, diante desta situação, todavia, temos uma certeza: os critérios de verdade não podem ser os mesmos para a vigília e para o sonho. Pois, se o fossem, o pensamento verdadeiro seria um sonho - conclusão inaceitável. Esta certeza, note-se, independe de nossas experiências efetivas de sonho e vigília, pois, ainda que sem critérios referenciais para distinguir os respectivos conteúdos, o pensamento verdadeiro não pode ser um sonho. 
Essa é uma situação típica em que afirmamos ser possível duvidar, i.e., pôr em questão a veracidade dos conteúdos da percepção. A operação epistêmica de duvidar corresponde, como nos casos anteriores, a uma experiência perpassada pela linguagem. De fato, não seria possível identificar esta operação e aplicá-la efetivamente sem a prévia organização de nossa experiência cognitiva por meio do conceito de dúvida. Nada melhor, então, do que considerar, sob este ponto de vista mais voltado para a linguagem, o sempre vigoroso argumento do sonho em sua aplicação canônica, feita por Descartes, para apreciar seu interesse lingüístico e suas conseqüências.

Como reproduzir, então, a aplicação canônica do argumento à situação de sonho e vigília, tal como apresentada acima? O argumento é aplicado para questionar a possibilidade de termos acesso ao pensamento verdadeiro, sublinhando, para isto, que a comunidade referencial dificulta, ou mesmo impossibilita, o discernimento entre os dois estados: se não possuímos critérios referenciais para distingui-los, então todas minhas afirmações sobre o mundo exterior podem ser apenas o relato de imagens oníricas e, conseqüentemente, a negação dos conteúdos da percepção vigilante; esta chama a minha frente, crepitando na lareira, pode ser um sonho e falso o enunciado que a afirma. A dúvida só poderá ser superada pela indicação de algum critério de outra natureza, que permita instaurar a certeza, ou, pelo menos, a possibilidade do pensamento verdadeiro.

É importante sublinhar que a aplicação canônica limita o argumento às afirmações verdadeiras que põem positivamente a existência - limitação explicada pelo fato, certamente, de aí estar suposta uma particular concepção da percepção -; todavia, o argumento pode também ser aplicado, legitimamente, às afirmações verdadeiras ou falsas que negam a existência. Por exemplo, quando vejo que não está chovendo, se estiver desperto posso sempre duvidar da veracidade da respectiva afirmação, pois poderia estar sonhando. É possível, pois, duvidar tanto da verdade quanto da falsidade das afirmações positivas e negativas a respeito da existência de objetos e estados de coisas. O argumento não é aplicado em toda sua extensão porque poderia conduzir, como se vê, a estranhas conclusões: podendo ser falsas as afirmações feitas em vigília, e sendo o sonho a negação da vigília, bastaria 
substituir os valores de verdade dessas afirmações falsas para obter em sonho um caminho para a verdade. Uma outra dificuldade, ainda mais séria, seria distinguir entre a falsidade da vigília e aquela do sonho: se o sonho torna falsas as afirmações feitas em vigília, qual seria o valor de verdade em sonho de uma afirmação falsa feita em vigília? O argumento possui esta abrangência maior, e indesejável, porque põe em dúvida a própria decidibilidade das afirmações em geral sobre os conteúdos de nossas percepções e pensamentos expressos lingüisticamente: o simples ato tético já é indecidível. A aplicação canônica do argumento deixa escapar da dúvida as afirmações em vigília sobre a inexistência assim como as afirmações falsas.

$\mathrm{O}$ argumento é aplicado, pois, para indicar apenas que não há medida comum entre os critérios de verdade em sonho e em vigília, i.e., que a verdade ou falsidade em um caso nada afeta a verdade ou falsidade no outro. Por exemplo, sonho que chove e, ainda em sonho, abro a janela e vejo que chove; instantaneamente, despertando, digo "chove", abro a janela e vejo que chove. O critério que torna verdadeira esta última afirmação feita em vigília nada diz a respeito do valor de verdade da mesma afirmação feita em sonho. Do mesmo modo, podemos acrescentar, para os casos que negam a existência e são falsas as respectivas afirmações. Ainda que soubesse estar sonhando, se isto fosse possível, nada poderia concluir sobre o que não existe, e, a fortiori, sobre o que existe; o estado sonhador não altera o valor de verdade das afirmações vigilantes, ou melhor, não interfere em seus critérios de verdade, pois são universos de discurso sem medida comum. Em sonho, uma afirmação pode ser verdadeira exclusivamente no interior do próprio sonho - e reciprocamente, aliás, em vigília. Todavia, se há comunidade referencial entre os conteúdos lingüísticos das imagens oníricas e os da percepção desperta, o que nos levaria a afirmar que não há medida comum entre os critérios de verdade para os dois estados? Em outros termos, quais os fundamentos do argumento que permitem sua aplicação canônica se nada há que pareça endossar esta conseqüência: apesar da comunidade referencial dos conteúdos da percepção desperta e sonhadora, afirma-se a ausência de critérios de verdade comuns. 
Talvez a consideração dos sonhos de segundo nível, em estilo espinosista, possa trazer algum esclarecimento a este respeito. De fato, ao sonhar que sonhamos, julgamos as afirmações, pensamentos e percepções do sonho aplicando critérios de verdade da mesma maneira que os aplicamos em estado de vigília: reproduzimos juízos dogmáticos dizendo "sei que não sonho ao ver-me sonhando" e consideramos falsos ou sem comum medida os conteúdos do sonho sonhado, ou, então, reproduzimos juízos céticos afirmando "posso estar sonhando ao ver-me sonhando" e, também, consideramos falsos ou sem comum medida os conteúdos do sonho sonhado, assim como aqueles da própria percepção sonhadora atual. Qualquer que seja o valor de verdade de um conteúdo pensado ou percebido em vigília, o mesmo conteúdo, uma vez em sonho, ainda que de segundo nível, será considerado necessariamente falso ou sem comum medida com o da vigília. Se não for assim, i.e., se não forem estes os resultados de nossos julgamentos a respeito dos conteúdos de nossos próprios sonhos, em sonhos de segundo nível - situação, finalmente, esclarecedora dos fundamentos do argumento do sonho -, então, ao relatar estes sonhos de segundo nível diremos que ao julgar em sonho não aplicamos o conceito de sonho, ou que não o aplicamos corretamente, ou que aplicamos um outro conceito - talvez o de vigília -; ou, ainda, se alguém nos disser tais coisas, e não concordarmos, afirmará que não aprendemos a aplicar adequadamente os conceitos. Em outros termos, se formos capazes de aplicar adequadamente os conceitos de sonho e vigília, então aplicá-los-emos adequadamente nos próprios sonhos de segundo nível - ou, se não for o caso, pelo menos, nos relatos de tais sonhos. Tematizamos os sonhos, em sonhos de segundo nível ou em relatos de sonhos, por meio dos conceitos de sonho e vigília. Em outros termos ainda, nossa percepção é tética e assertiva - não, certamente, no sentido espinosista, mas fregiano, de que são momentos logicamente independentes, embora não empiricamente; o momento da asserção, entretanto, no caso dos sonhos de segundo nível, ou dos relatos de sonhos, incide sobre o estado mental do sonho, e apenas indiretamente sobre os conteúdos da respectiva percepção. É através do próprio conceito que são descritos e julgados esses conteúdos. 
O que nos esclarece essa situação a respeito dos fundamentos do argumento do sonho? Algo de aparentemente trivial, a saber, que o argumento tem como fundamento um elemento contido nas próprias definições dos conceitos de sonho e vigília, ou seja, a exigência de que devem ser contrários os respectivos estados, porque não podemos pensá-los como não contrários. Algo, portanto, externo ao próprio argumento e que é integrado à sua aplicação; algo introduzido como uma necessidade axiomática. O argumento explora esta necessidade deixando-a implícita, enquanto pressuposto, e enfatiza a falta de critérios referenciais. A eliminação da dúvida exige critérios de outra natureza.

\section{III}

Todavia, sem critérios referenciais para delimitar o sonho e a vigília, podemos reproduzir nos sonhos de nível superior não apenas juízos dogmáticos e céticos, como também descrições dos usos das palavras - como diria Wittgenstein! Sonhemos, pois, com uma descrição possível do contexto lingüístico em que é aplicado o argumento do sonho, para apreciar sua virtual eficácia no interior deste contexto, e, talvez, esclarecer melhor a natureza de seu fundamento.

Em primeiro lugar, parte-se de duas situações em que, sendo comuns as referências da percepção e do pensamento, devem ser simétricas as formas de aplicação dos critérios de julgamento: os valores de verdade das respectivas expressões lingüísticas, ainda que sem comum medida, serão uma função do que for verificado ocorrer ou não ocorrer no interior de cada sonho e de cada situação de vigília; em outros termos, são situações lingüisticamente equivalentes. Se aplicarmos o conceito de verdade aos conteúdos do sonho, aplicá-lo-emos tal como é aplicado em vigília, i.e., segundo critérios de verificação colhidos no interior do universo de discurso em que é aplicado - e não fora dele, onde, aliás, perderia seu sentido. A afirmação de que vejo um cavalo alado só pode ser concebida como verdadeira se vir, de 
fato, um cavalo alado em sonho. Em segundo lugar, lança-se mão de um critério de natureza mental para distinguir as duas situações: o estado de consciência, presente na vigília e ausente nos sonhos. Este critério vem satisfazer a exigência a priori de se distinguir os dois estados e assegurar que o sonho corresponda ao domínio de nossas representações subjetivas inconscientes e seja a negação da vigília, enquanto a esta possa corresponder o domínio dos critérios públicos de verdade e falsidade, sendo a negação do sonho. Ora, o argumento permite mostrar - para além de sua aplicação canônica - que o estado de consciência é um critério muito frágil, apesar de necessário, uma vez que ao sonhar temos não simplesmente falta de consciência, mas, "pseudoconsciência", a saber a crença de estarmos despertos. Daí a força do argumento - implícita à sua aplicação canônica -, ao generalizar a dúvida mostrando que a crença falsa em um estado de coisas tornase mais forte do que a certeza, na falta de qualquer critério referencial preciso para distinguir entre os estados mentais. Não apenas o julgamento pode ser falso, como, principalmente, o próprio ato tético torna-se indecidível sonhador ou vigilante? Os critérios aplicados para opor necessariamente sonho e vigília são vagos, solicitando, então, critérios de nível superior que permitam tornar precisa a exigência de contrariedade presente em suas definições.

Não seria possível, entretanto, indicar fundamentos, ainda que fugazes, não definitivos, nem absolutos, que não nos deixassem esperar mais e obter menos?

O modelo referencial da significação - no sentido mais amplo em que 0 apresenta Wittgenstein, assim como no sentido mais restrito, presente na concepção extensional da linguagem, a saber, em que são consideradas exclusivamente as relações externas entre as proposições - aplica-se de maneira bastante adequada aos conteúdos do pensamento e da percepção nos sonhos em sua relação com os da vigília. De fato, permite sublinhar a proximidade lingüística, já apontada, entre as duas situações mostrando as fortes filiações extensionais entre os respectivos conceitos que exprimem seus conteúdos. Basta aqui indicar o exemplo, ainda superficial, mas já notável, da coincidência entre o tempo da percepção atual e o do relato de seus con- 
teúdos, em sonho e em vigília: "Estou percebendo esta chama crepitando na lareira" é um enunciado que se aplica em sonho assim como em vigília, exprimindo, por sua forma lingüística, o tempo atual da percepção. Isto mostra que o relato de nossa percepção está sempre submetido à condição da forma lingüística dos próprios conteúdos da percepção, tanto em sonho quanto em vigília, da mesma forma que esta é também uma condição para que o próprio argumento do sonho possa ser aplicado. De fato, se os conteúdos da percepção desperta fossem lingüisticamente inexprimíveis, os conteúdos de nossos sonhos seriam, igualmente, inexprimíveis; não seríamos capazes de relatá-los, permaneceriam silenciosos na interioridade de nossas experiências privadas; daí o tempo lingüístico de sua expressão coincidir com o presente atual de sua percepção, assim como quando estamos despertos. A força do argumento vem, neste sentido, da crença profunda que depositamos na percepção quando ela é exprimível lingüisticamente; tratase, na verdade, de uma certeza: estamos certos de perceber mesas, pessoas e situações, em vigília como em sonho, porque conhecemos as convenções lingüísticas de nossa percepção. Aprendemos a associar palavras e enunciados a objetos, pessoas e situações e, em sonho assim como em vigília, conservamos esse conhecimento que exprimimos lingüisticamente ao relatar aquilo que dizemos perceber.

Seria, aqui, inútil lançar mão da noção de consciência para dar conta deste saber como fazer prático-simbólico que não mais passa por um saber que teórico de quais são as regras que estão sendo aplicadas: adquirimos uma habilidade referencial que não mais precisa ser tematizada para ser exercida, tornou-se uma maneira natural de perceber e pensar, até mesmo durante o próprio sonho. Seguimos cegamente regras ao perceber e pensar, i.e., não mais pensamos nas regras que orientam nossa percepção e nosso pensamento. Se não for assim, ou se esta solução não for satisfatória, seremos levados a invocar um estado mental consciente enquanto princípio esclarecedor das regras que estão sendo aplicadas. Esta solução, todavia, não pode evitar a remissão indefinida a novos estados conscientes de níveis superiores que permitam tornar não ambíguas as inevitáveis imprecisões contidas nas formulações das regras. A noção de consciência, entretanto, pode- 
rá ser mobilizada, legitimamente, em outro nível, i.e., quando se trata de tematizar o próprio estado mental em que se atualiza a percepção, e não mais seus conteúdos. Ora, o modelo referencial fornece, no primeiro caso, critérios bastante claros para a aplicação adequada dos conceitos na organização da percepção, vigilante ou sonhadora; todavia, no segundo caso, não mais fornece tais critérios. É que, neste segundo caso, os conceitos mentalistas não são passíveis de uma análise exclusivamente extensional, i.e., não são redutíveis a elementos referenciais - e este é o outro aspecto da situação que também dá força ao argumento do sonho.

Deste ponto de vista, o interesse do argumento consiste em ressaltar a falta de um fundamento definitivo para a certeza em nossa percepção, pois é sempre possível duvidar daquilo que nossos sentidos indicam como algo que existe independentemente da própria percepção - é quando o modelo referencial não fornece critérios para distinguir sonho e vigília. Ainda aqui, entretanto, não é pertinente duvidar das convenções lingüísticas que organizam a percepção e sustentam nossa certeza naquilo que afirmamos perceber. Se os sentidos podem enganar-nos é por falta de critérios que permitam distinguir os próprios estados mentais perceptivos, e, também, porque o modelo referencial impõe-se aos sentidos em geral, sonhadores e vigilantes. Mas não duvidamos daquilo que afirmamos perceber e que somos capazes de exprimir lingüisticamente; a certeza de que percebo esta chama crepitante na lareira não é abalada pela dúvida legítima de ser esta percepção vigilante, e não sonhadora: posso duvidar da existência desta chama, mas não de que é uma chama que percebo, e não, por exemplo, o mar revolto ou um cão.

Dúvida e certeza parecem, pois, coincidir em um ponto-limite: os critérios normativos e convencionais para a aplicação dos conceitos. Eis um resultado interessante da aplicação do modelo referencial ao contexto lingüístico do argumento do sonho. Em primeiro lugar, a ausência de critérios precisos para distinguir entre os conteúdos percebidos em sonho e em vigília indica que aplicamos as mesmas regras referenciais das palavras para orientar nossa percepção nos dois casos; indica que, se o modelo referencial é aplicado com sucesso na orientação da percepção e na descrição de seus conteúdos, deixa de sê-lo quando se trata de aplicar critérios mentalistas 
para distinguir os estados de vigília e sonho - insucesso, por sua vez, legitimamente explorado pelo argumento do sonho. Em segundo lugar, os critérios oriundos da aplicação do modelo referencial são de natureza lingüísti$\mathrm{ca}$, são regras normativas que dizem respeito às aplicações das palavras, i.e., aos conceitos, e não aos conteúdos da percepção: não é esta chama crepitando na lareira que determina o conteúdo de minha percepção, desperta ou sonhadora, mas, pelo contrário, é uma regra lingüística que nos permite identificar esta região da experiência, em sonho ou vigília, e orientar a percepção por meio da palavra "fogo". Na ausência de conceitos, esta chama crepitando na lareira poderia, ainda, está claro, ser percebida em sonho ou em vigília, mas não poderia ser expressa enquanto conteúdo da percepção: seria algo ou um nada, assim como tantas coisas que percebemos e para as quais não temos ainda, talvez jamais tenhamos, palavras e conceitos. Neste caso, não seria sequer aplicável o argumento do sonho, na falta dos conceitos de sonho e vigília. Em terceiro lugar, conseqüentemente, não duvidamos, na verdade, dos próprios sentidos, de suas convenções; podemos duvidar apenas quando não houver critérios que permitam organizar a experiência e identificar as formas da objetividade: não duvido que é uma mesa que percebo, mas posso duvidar sobre a natureza do estado mental de minha percepção, pois não há critérios que permitam sua identificação.

Por outro lado, todavia, o modelo referencial da significação encobre a importância de certas diferenças nos usos das expressões lingüísticas de conteúdos perceptivos. Uma vez que os conteúdos das imagens oníricas e os da percepção desperta coincidem nas referências habituais das palavras, tende-se a relegar a diferença entre expressões que relatam conteúdos sonhados e as que descrevem conteúdos percebidos atualmente em vigília ou em sonho: no primeiro caso, as descrições não são apresentadas no tempo presente da enunciação do relato. A percepção atual, seja em sonho ou em vigília, coincide, normalmente, como salientamos, com o tempo presente da enunciação quando a descrição incidir sobre a própria percepção, ou melhor, sobre suas referências lingüísticas. Todavia - e este é o caso que gostaríamos de salientar -, quando se trata de relatar conteúdos da percepção qualificada de sonhadora, fica excluída a forma do presente lingüístico. A obser- 
vação é trivial, mas torna-se importante ao considerarmos os casos em que esta regra lingüística não é aplicada. De fato, ao usar o presente do indicativo para relatar os conteúdos de meu sonho dizendo "estou sonhando", estarei brincando, fingindo retoricamente estar sonhando - aliás, como o fez Descartes - ou, então, estarei aplicando um outro conceito, vizinho ao de sonho, por exemplo, o de alucinação, i.e., alguém que estaria descrevendo o que percebe atualmente sob os efeitos de uma droga sem perder, todavia, e mais uma vez, a consciência de estar desperto e drogado. É interessante notar que em todos esses casos, de transgressão da regra lingüística do relato de sonhos, quem relata assume o ponto de vista desperto - ainda, como vimos, quando está sonhando que sonha e reproduz um juízo dogmático no sonho de segundo nível. Ora, ao fazer isso, o indivíduo será compreendido em sua brincadeira, ou será levado a sério em sua argumentação - assim como levamos a sério, até hoje, Descartes -, ou será considerado em crise de alucinação, mas não em estado de sonho, ou, ainda, no caso do sonho dogmático de segundo nível, estará transgredindo a regra, mesmo que sem maiores consequiências práticas e públicas. Embora não haja qualquer necessidade extrínseca envolvendo nossos conceitos habituais - e o conceito de sonho, em particular -, o uso que deles fazemos não é um sonho; se o fosse, seria um sonho público e não privado, idéia igualmente contrária a nosso conceito de sonho. Tanto é assim que podemos "brincar" com palavras, "argumentar" retoricamente e "alucinar" ao transgredirmos aquela simples regra lingüística do relato dos sonhos, i.e., seremos ainda assim compreendidos; novos conceitos serão aplicados para identificar nossos comportamentos dando-lhes novos sentidos. Ao realçar esta regra de uso das expressões lingüísticas, damos um pequeno passo no sentido de perceber que sua transgressão implica a organização de novas relações entre conceitos. Os estados mentais de sonho e vigília são ligados conceitualmente a outros estados e comportamentos em que voltam a ser aplicados critérios já conhecidos. Por exemplo, a brincadeira com palavras e a argumentação retórica são, certamente, considerados comportamentos conscientes, enquanto a alucinação pode sê-lo em alguns casos, mas não em outros. Há, pois, uma trama conceitual ligando estados mentais e comportamentos indepen- 
dentemente das referências lingüísticas e dos experimentos que possam ser realizados a este respeito. É a mesma necessidade conceitual que aproxima e opõe estados e comportamentos diferentes.

E retornamos, assim, ao argumento do sonho quando insiste sobre a natureza não-operatória dos critérios mentalistas para distinguir sonho e vigília - e, extensivamente, tantos outros estados e comportamentos aparentados. Ora, a partir desta legítima constatação, o argumento, em sua aplicação cartesiana, salta para uma conclusão que não atenta para a importância da organização lingüística imposta à percepção. A partir da inaplicabilidade dos critérios mentalistas - consciência e pseudoconsciência sendo apenas suposições explicativas para experiências vividas subjetivamente e não correspondendo a conceitos analisáveis em suas relações externas, segundo o modelo referencial -, conclui com a inexistência de critérios extramentais, claros e distintos, sobre a existência dos objetos do mundo exterior. A aplicação cartesiana reduz, aqui, certamente, sua força original ao velar a função constitutiva da linguagem na organização dos conteúdos da percepção em geral, desperta ou sonhadora. Embora sem fundamentos mentais definitivos e claros e ainda no interior do modelo referencial da significação, quando, de fato, os sentidos podem enganar-nos, a linguagem não nos enganará se tentarmos olhar e ver o que nós próprios fazemos com as palavras e os conceitos, tal como propõe Wittgenstein.

Neste ponto, poderíamos distinguir entre a questão levantada pelo argumento do sonho e sua conclusão: a questão, de que posso sempre duvidar de estar desperto ao fazer afirmações sobre objetos e estados de coisas que digo perceber atualmente, é a premissa da conclusão, esta, realmente cética, de que, por prudência, para evitar o dogmatismo, devemos duvidar a respeito da existência do próprio mundo exterior. A premissa não é propriamente cética, pois apenas expressa a ausência de critérios claros e distintos - ou, no contexto lingüístico em que introduzimos o argumento, critérios referenciais extralingüísticos e operatórios - para decidir. Cética é a conclusão. Como pode, então, ganhar corpo o ceticismo, baseado naquela simples constatação sobre a falta de tais critérios? É que, embora sem critérios dessa natureza para indicar a que tipo de objetividade aplicar o conceito de 
consciência, aprendemos uma série de convenções permitindo sua aplicação: por exemplo, uma norma que permite opor os comportamentos de sonho, alucinação e algumas patologias mentais, comportamentos estes que conhecemos por experiência direta e aos quais aplicamos com sucesso o modelo referencial; não sabemos muito mais do que isto. Se fizermos filosofia, diremos, além disso, que a consciência é aquilo que deve existir mentalmente para que o pensamento verdadeiro não seja uma ilusão, um sonho ou uma quimera - e muitas outras conseqüências, como para explicar que a linguagem seja mais do que um amontoado de sons e sinais sem sentido, que nossos comportamentos sejam mais do que movimentos físicos sem sentido, etc.; muito mais do que isto, também não sabemos. A partir daí, podemos formular teorias científicas ou sistemas filosóficos para explicar isso que deve existir e que é a negação do sonho, alucinação, loucura e a afirmação do sentido. Embora sem critérios referenciais aplicáveis, trata-se de uma necessidade conceitual que organiza uma família extensa de outros conceitos, aproximando-os e opondo-os. Mesmo sem poder indicar o conteúdo desta caixa-preta, supomos que haja aí um conteúdo determinado, e que é esse conteúdo que permite explicar situações e comportamentos importantes para nós. São estas explicações, talvez misteriosas e insondáveis, pouco claras e distintas, que vêm apaziguar nossas dúvidas, pelo menos provisoriamente. É sobre esta base considerada frágil que toma fôlego a conclusão cética.

Ora, estas aplicações dos conceitos são frágeis como fundamento porque falta-lhes a referência, e é isto que o cético radical procura para apaziguar sua dúvida retórica. De fato, não há um qualquer critério extralingüístico preciso que nos permita afirmar com certeza que estamos sonhando quando sonhamos; pelo contrário, nesse estado, acreditamos estar despertos, i.e., nossos sentidos nos enganam ao reproduzir as convenções e aplicar os conceitos aprendidos em vigília. $\mathrm{E}$ nem poderia haver um tal critério, uma vez que os critérios para o estado sonhador são fornecidos na vigília, de tal maneira que para saber que sonho ao sonhar, precisaria estar desperto. Eis um exemplo de definição de conceitos, e não o resultado de algum experimento; eis um exemplo de organização lingüística de experiências 
individuais privadas. Assim, é sempre possível duvidar que estamos aplicando nossos conceitos em vigília. Mas por que esta constatação sobre a falta de critérios extralingüísticos deveria conduzir exclusivamente à conclusão de que devemos duvidar, por prudência e para evitar o dogmatismo, da aplicação em geral dos conceitos a objetos existentes no mundo exterior - se o dogmatismo não se instala sobre a falta de critérios precisos, mas sobre a pretensa existência de critérios precisos, i.e., sobre a postulação de sua existência? O passo é pequeno, mas não é inevitável, e nem justificado. A ausência de critérios precisos não convida apenas à dúvida prudente, mas também, e, principalmente, à indagação de por que, apesar disso, persistimos em acreditar nos sentidos. Os sentidos podem enganar-nos, como indica retoricamente o argumento do sonho, a respeito do próprio estado de vigília e, em conseqüência, a respeito da existência do mundo exterior e, portanto, da aplicação a ele dos conceitos. Mas não nos enganam a respeito do que exprimimos lingüisticamente, em sonho ou em vigília, i.e., das convenções reproduzidas em sonho e aprendidas em vigília. Acreditamos nos sentidos porque é a mesma linguagem, são os mesmos conceitos presentes no sonho e na vigília. De tal modo que, para prosseguir duvidando, será preciso introduzir um princípio de ordem superior - ou, para evitar dificuldades adjacentes a este momento da aplicação canônica do argumento, bastará introduzir em cena o personagem fictício de um gênio brincalhão. A conclusão cética parece justificar-se, pois - independentemente deste recurso retórico e ficcional que responde à arquitetura hiperbólica da argumentação cartesiana -, em face da ausência de critérios lingüísticos precisos que permitissem indicar precisamente a referência dos conceitos perceptivos - estados mentais, e, menos radicalmente, propriedades e relações entre objetos empíri$\cos$. As regras extensionais da linguagem não se aplicam aos detalhes da experiência perceptiva, nem, a fortiori, aos conceitos mentalistas. A dúvida que daí emerge não é abalada pela certeza nas convenções lingüísticas, pois, mesmo pelo contrário, exprime a imprecisão das próprias convenções. Poderíamos, pois, deixar em suspenso o gênio brincalhão, uma vez que o ato tético permanece indecidível até sem sua simpática presença. Aquilo que nos faz acreditar nos sentidos é o fundamento para a dúvida cética. 
Ora, como sabemos, a conclusão do cético radical, a respeito da aplicabilidade em geral dos conceitos, pode ser superada mediante um critério preciso, i.e., um critério que será aceito pelo próprio cético. Descartes apresenta um tal critério por meio da figura do Cogito - e, ao fazê-lo, revela, indiretamente, sua natureza lingüística. De fato, ao admitir que não posso pôr em dúvida meu próprio ato de duvidar e, com isto, que estou pensando - ainda que em sonho -, não mais posso duvidar, pelo menos, da existência do pensamento. Mas isto significa que não posso duvidar, desperto ou sonhando, que aplico o conceito de dúvida, e, portanto, que aplico a linguagem, pelo menos neste caso, desperto ou sonhando, para orientar meu pensamento. Daí só posso concluir, clara e distintamente, que pensar é aplicar conceitos - aprendidos em vigília ou em sonho, pouco importa -, conceitos oriundos de convenções lingüísticas persistentes que dirigem minha percepção externa e interna; sei que penso, estou certo e consciente disto quando e enquanto aplicar tais convenções. Ainda que sonhando, não mais posso duvidar que penso, ou melhor, que aplico convenções lingüísticas por meio das quais gero a certeza clara e distinta de sua própria aplicação.

Todavia, como vimos, a esta certeza já havíamos chegado antes mesmo da introdução do gênio brincalhão: certeza em uma simples convenção lingüística. De fato, a certeza de que três mais dois é igual a cinco equivale àquela de que percebo uma mesa, e não uma cadeira, desperto ou em sonho, pois, embora sustentadas por provas rigorosas, as verdades matemáticas repousam, assim como as referências das palavras para a percepção, em convenções lingüísticas: se realizamos corretamente um cálculo, é apenas porque apreendemos corretamente suas regras, e não porque existem verdades matemáticas que nos coagiriam até durante nossos sonhos. Mas isto significa apenas que a certeza quanto ao exercício da dúvida corresponde à certeza em mais uma convenção lingüística - a qual, nesta manobra retórica de Descartes, apresenta-se, por assim dizer, encarnada no personagem do gênio. Todavia, como se trata de uma manobra retórica, de um argumento levado ao limite, o peso argumentativo da figura do gênio incide sobre a própria coerência do discurso cartesiano, e não mais sobre seus conteúdos: trata-se de resguardar este discurso da contradição. De fato, se aceitamos 
pôr, ainda que retoricamente, um princípio do engano, gerador da dúvida, então não podemos, em seguida, e sem contradição, negar este mesmo princípio - afirmando que podemos ainda duvidar que duvidamos, ou melhor, negando o princípio que nos faz duvidar e que acabamos de introduzir. Uma vez aceito o gênio enganador, devemos assumir, com certeza, o fato de que duvidamos até então, e isto em nome da não-contradição do próprio raciocínio. Resguardada, assim, a coerência do discurso, resta, como resultado, apenas mais uma convenção lingüística de que temos certeza: a aplicação do conceito de dúvida.

Afastamo-nos, aqui, está claro, da aplicação canônica do argumento, solidária que é de uma determinada concepção das proposições matemáticas, geométricas e das que exprimem os conteúdos da percepção. De nosso ponto de vista, pois, a figura do gênio poderia intervir mesmo antes das certezas matemáticas e geométricas, para abranger a certeza nas convenções lingüísticas em geral - o que significa, por outro lado, que essa figura poderia também ser eliminada. Mas, se for assim, será ainda preciso resguardar do engano, e, portanto, da possibilidade da dúvida, a própria certeza do Cogito: resguardá-la da ameaça, agora, da ilusão solipsista. Uma vez mergulhados no oceano das convenções lingüísticas, e sem mais verdades autônomas servindo de amparo claro e distinto, poderíamos acreditar que estamos certos de algo sem sermos, entretanto, capazes de apresentar os critérios para nossa certeza: nada mais nos engana, nem o estado sonhador nem o gênio brincalhão, e podemos, então, obter a certeza de que aplicamos adequadamente o conceito de dúvida; todavia, esta certeza permaneceria apenas uma vivência subjetiva - tal como a sensação de dor ou a emoção amorosa que não somos capazes de descrever a partir de nossa intimidade pessoal -, se não pudéssemos apresentar sua identidade pública. E isto só poderá ser realizado por meio de uma descrição: sei que não se trata de uma ilusão quando for capaz de relatar a aplicação feita do conceito de dúvida e seus resultados; o relato é a garantia necessária de que a certeza não é, pelo menos neste caso, uma ilusão privada. De fato, se fosse incapaz de relatar a aplicação que faço do conceito de dúvida, o conceito de consciência não seria aplicável no contexto do argumento do sonho: o exer- 
cício consciente da dúvida ficaria limitado a uma vivência subjetiva e incomunicável, talvez pré-lingüística, de qualquer modo, não-lingüística. Sei que aplico o signo, mas não sou capaz de exprimi-lo lingüisticamente, i.e., penso mas não sou capaz de relatar o que pensei. Mas, se duvido sem ser capaz de dizê-lo, sem ter palavras para exprimir esse pensamento, como posso saber que penso? Só posso saber, de fato, que sou consciente de meus próprios estados porque conheço as convenções lingüísticas dos conceitos que aplico para organizar minha experiência pessoal privada - e não porque perceba um estado mental específico que seria a referência da respectiva palavra.

O conceito de consciência é aplicado, neste sentido, à expressão lingüística das regras que são aplicadas, e não a uma suposta referência mental esclarecedora do sentido das regras; a expressão lingüística do saber que poderá ser equivocada, inadequada ou mesmo falsa, relativamente a determinados critérios, mas será sempre o relato de regras que permitem organizar, de alguma maneira, a ação e o pensamento. Não agiremos cegamente quando formos capazes de usar a linguagem para dar forma à expressão dos critérios convencionais que permitem, por sua vez, organizar nossa ação e pensamento destacando neles aspectos considerados importantes. Podemos afirmar que somos conscientes unicamente pela aplicação do conceito de consciência - ou melhor, do relato de sua aplicação, uma vez que há lugar para diferentes aplicações. O estado consciente não é, pois, deste ponto de vista, o conteúdo mental previamente existente a ser expresso por meio dos relatos das aplicações do conceito, mas, inversamente, é uma variável a ser preenchida por cada aplicação do conceito, ou melhor, um fragmento de nossa experiência privada a ser constituído pelas respectivas aplicações conceituais. O estado consciente não é uma ilusão solipsista, mas um comportamento lingüístico.

É, finalmente, a expressão lingüística da experiência pessoal privada que torna criterial e normativa uma tal experiência, i.e., torna-a um aspecto da situação instituído como norma para identificar formas da objetividade mental, como a dúvida e a certeza. Por exemplo, aquele aspecto de nossa experiência privada que consiste em negar uma afirmação considerada ver- 
dadeira e apresentar esta negação como apenas plausível; ou, então, aquele aspecto dessa mesma experiência privada que consiste em apresentar como tese verdadeira uma afirmação, negativa ou positiva. Tais aspectos de nossa experiência privada permaneceriam silenciosos e inefáveis sem a intervenção de palavras a eles associadas no interior de uma situação em que se trata de afirmar e negar teses a respeito do mundo, de objetos e estados mentais. Os conceitos de dúvida e certeza tornam públicos e normativos fragmentos de nossa experiência privada, por meio de sua expressão lingüística - assim como o conceito de consciência.

Ganhamos, com isto, um critério mais preciso para identificar o pensamento, ou melhor, para a aplicação do respectivo conceito, quando filosofamos; mas não qualquer critério para decidir se sonhamos ou se estamos acordados. A atividade do pensamento independe de tais estados, diz-nos o Cogito - assim como a linguagem, diríamos. O conceito de consciência não é definido enquanto uma atividade mental - por exemplo, enquanto uma das formas de pensamento, como o é o conceito de dúvida -, mas enquanto um estado mental - como os estados de expectativa, esperança, felicidade, amor e ódio. Se é possível sempre aplicar uma atividade a si própria, sob a forma de uma operação determinada, e daí obter um resultado positivo, o mesmo não ocorre com os estados. É que os estados mentais são definidos apenas como o contexto no interior do qual ganham um sentido determinado as aplicações dos conceitos de atividade mental. Assim, por exemplo, faz sentido afirmar que duvido tendo a expectativa de chegar à certeza, ou, ainda, que duvido sendo consciente desta minha atitude, mas não faz sentido afirmar que exerço atividades de expectativa e consciência duvidando que espero e que esteja consciente. Se os estados de expectativa e consciência forem tratados como atividades, será apenas no sentido de que permitem modalizar as afirmações deles decorrentes - que serão marcadas lingüisticamente, como, por exemplo, "ainda não sei" e "sei que não sei" -, mas não o será no sentido operatório a que uma atividade pode sempre ser reduzida - por exemplo, a dúvida pode ser interpretada como uma operação de negar qualquer afirmação considerada verdadeira, falsa ou evidente e, em seguida, indicar a plausibilidade da negação. Assim, ao aplicar uma opera- 
ção a si própria obtemos um resultado positivo, que será, também, uma operação, ao qual podemos atribuir um valor de verdade: ao duvidar que duvido, substituo a operação de negar pela de afirmar positivamente o ato de negação, ou, se quisermos, nego a negação de segundo nível. Todavia, ao aplicar um estado a si próprio não obtemos nenhum resultado positivo, senão uma remissão indefinida: a consciência da própria consciência não parece ser um estado mais rico ou profundo, nem uma operação que pudesse ser aplicada à consciência e gerar algum resultado positivo, i.e., que pudesse ser aplicado desencadeando uma nova série de aplicações possíveis. Se não fosse assim, a consciência de segundo nível poderia gerar um critério de certeza para decidir que estou acordado e não mais sonhando. É justamente nesta lacuna que se insinua o argumento do sonho. E, novamente, o conceito de consciência mostra sua natureza não-extensional: se não mais posso duvidar que penso ao aplicar o conceito de dúvida, posso, entretanto, estar sonhando e, portanto, apenas acreditar que estou desperto; a certeza do Cogito não elimina a dúvida a respeito da vigília, embora permita descartar a experiência solipsista através do relato da aplicação do conceito. Não mais duvidaremos que existe uma linguagem pervadindo nossas experiências privadas, mas sempre podemos prosseguir duvidando se estamos acordados ou sonhando, conscientes ou falsamente conscientes, ao aplicarmos a linguagem.

Chegamos, assim, à situação, aparentemente paradoxal, de que se a expressão lingüística da dúvida permite afastar a certeza do domínio solipsista, por outro lado, os próprios conteúdos do sonho deixam de ser exclusivamente privados, e a certeza clara e distinta não é exclusiva da vigília, uma vez que podemos ainda estar sonhando. É a composição entre estado consciente e estado vigilante que não resiste à análise, uma vez que são aplicados critérios de mesma natureza a situações diferentes: por um lado, o critério lingüístico, claro e distinto, aplicado à experiência de aplicação do conceito de dúvida a si próprio, que leva à certeza do exercício do pensamento, ao reconhecimento desta aplicação conceitual, em sonho ou vigília; e, por outro lado, a definição, de caráter necessário, unindo, indissoluvelmente, e independente de qualquer experiência, consciência e vigília, e ex- 
cluindo o sonho. Para compatibilizar a certeza quanto à aplicação do conceito de dúvida com a necessária exclusão do sonho, assegurando, desta maneira, que o pensamento não é uma mera representação da imaginação sonhadora, mas um resultado da atividade desperta, será preciso, como sabemos, recorrer a um princípio de ordem superior. É este, pelo menos, o caminho trilhado pela aplicação cartesiana do argumento, ao valer-se, pela segunda vez, de um princípio dessa natureza: a primeira, para prosseguir, ainda que retoricamente, na dúvida, quando esta não mais parecia ser possível, e, agora, para escapar ao solipsismo transcendental do Cogito, ou, mais ainda, de nosso ponto de vista, da ameaça que vem a sofrer por parte do estado sonhador.

E retornamos, assim, à dúvida prudente do cético, mas ineficaz em face de nossa crença profunda nas convenções lingüísticas da percepção. Tenho certeza de que penso, mas não sei se estou sonhando ou desperto, a linguagem não me fornece critérios precisos para decidir. Resta, pois, a questão: a falta de critérios precisos de identificação justifica a persistência da dúvida, ainda que prudente, a respeito da aplicação dos conceitos? Seria pertinente duvidar quando a dúvida for meramente possível?

\section{IV}

Ao salientarmos o aspecto lingüístico envolvido na definição dos estados de sonho e vigília, o argumento do sonho ganha maior interesse e, paradoxalmente, perde sua aparente eficácia. Como vimos, o argumento se apóia em uma norma, não em um fato: não sabemos, de fato, que sonhamos ao sonhar, mas, principalmente, por definição, não podemos sabê-lo. Não apenas não encontramos critérios precisos para distinguir os dois estados, mas, pelo contrário, encontramos uma definição que impossibilita tal distinção. Para exprimir uma situação em que pudéssemos saber que sonhamos ao sonhar, seria preciso aplicar outro conceito, não mais o de sonho; o conceito de sonho enclausura o estado mental de vigília. E, por outro lado, o 
argumento se apóia, também, como observamos, em uma exigência da razão, cuja consequiência é uma diferença de direito, mais do que de fato, entre os dois estados mentais - a verdade não é, de fato, um sonho, mas, principalmente, não pode sê-lo. Para exprimir uma situação em que fosse possível pensar verdadeiramente em sonho, seria preciso aplicar um outro conceito de verdade - tal como ocorre, por exemplo, na ficção; o conceito de verdade enclausura, igualmente, o estado mental de vigília. Deparamos, pois, apenas com definiçõos conceituais, i.e, com normas lingüísticas organizando experiências perceptivas - referenciais, no caso da percepção externa, e mentalistas, no caso da percepção interna.

Ao ganhar em interesse, o argumento do sonho, assim como também sua superação, pelo Cogito, perde em eficácia. Limita-se à simples constatação de que são definições convencionais de natureza lingüística o fundamento tanto da indecidibilidade de nossas afirmações em geral, em sonho ou vigília, quanto da primeira certeza - e, não mais, nem a existência de estados mentais indiscerníveis, nem a de atividades mentais irrecusáveis, por corresponderem a idéias claras e distintas. Não mais será pertinente a dúvida, i.e., a aplicação reiterada desta operação, uma vez que não tem sentido aplicá-la a uma simples definição conceitual: não é pertinente duvidar de uma definição em geral, nem, a fortiori, por não fornecer critérios para distinguir precisamente entre estados mentais; tampouco será pertinente a certeza, i.e., invocar esta atividade mental a respeito de uma simples definição conceitual em geral, nem, a fortiori, por permitir que uma operação seja aplicada a si própria. Em ambos os casos, tanto da indiscernibilidade entre estados mentais, quanto da reflexividade da operação de negação, trata-se, apenas, como diz Wittgenstein, de agir segundo regras conceituais e constatar que é assim que procedemos ao exprimi-las lingüisticamente - tal como fez Descartes. Ao exprimir nossa dúvida quanto à natureza dos conteúdos perceptivos e nossa certeza quanto a operações do pensamento, não estamos, na verdade e contrariamente às aparências, julgando a respeito de conteúdos extralingüisticos, afirmando-os ou negando-os; estamos apenas aplicando conceitos segundo as normas que aprendemos e que somos capazes de reproduzir. É, certamente, o modelo referencial da significação que 
nos leva a acreditar que julgamos conteúdos extralingüísticos ao afirmarmos duvidar da discernibilidade dos estados de sonho e vigília, assim como ao afirmarmos estar certos da existência do pensamento. Perde-se de vista, com isto, a função constitutiva da linguagem na organização de nossa experiência, externa e interna; ou melhor, que a linguagem fornece os modelos da objetividade física e mental por meio de sua expressão lingüística. A expressão lingüística da percepção externa e interna indica quais são os conceitos aplicados e, conseqüentemente, exibe as diferentes formas de organização da experiência, umas, confusas e imprecisas, outras, claras e distintas. Neste nível elementar, em que se situam o argumento do sonho e o Cogito, os conceitos de dúvida e certeza não se aplicam aos conteúdos da percepção, uma vez que não há ainda qualquer conteúdo extralingüístico, mas apenas normas lingüísticas, i.e., conceitos. Ainda que nada exista fora da linguagem, nem objetos exteriores, nem operações ou estados mentais, existem, todavia, conceitos, i.e., normas que organizam expressões a respeito do que supomos existir além da linguagem. A percepção nos leva a fazer tais suposições; entretanto, a percepção é pervadida por conceitos. A expressão lingüística dos conteúdos perceptivos permite provar indiretamente a existência daquilo que não se pode provar, com clareza e distinção, sem o auxílio de uma tese ontológica forte, a da separação entre pensamento e extensão: é esta separação de princípio que permite adquirir a idéia clara e distinta da existência do pensamento. Ao gerar conceitos, a atividade lingüística permite, também, provar indiretamente a existência daquilo que não se pode provar diretamente, com clareza e distinção, sem o auxílio de algum princípio de ordem superior, a saber, provar a existência do mundo exterior.

Separação de princípio entre pensamento e extensão, por um lado, e, por outro, auxílio de um princípio superior, eis dois elementos de que pode fazer economia uma concepção pragmática da significação lingüística ${ }^{(1)}$.

O conceito, pragmaticamente concebido, é o ponto de união entre pensamento e extensão, e, por isto mesmo, permite aplicar reflexivamenté o conceito de dúvida assim como escapar ao isolamento da atividade reflexiva pura. 
Com o projeto de descrição fenomenológica, de fato, damos um passo além de Descartes, ao explorar a subjetividade enquanto imanência transcendental, i.e., tornando-a autônoma e independente de um princípio superior de realidade. Abre-se, assim, caminho para uma nova concepção de representação simbólica em geral. Todavia, esta subjetividade fenomenológica apresenta-se, em Husserl, como tributária de uma consciência omnipresente aplicada como operador com a função constituinte do sentido da objetividade. Um tal operador, contudo, não deixa de evocar, por seu caráter profundo e indevassável, aquele outro mistério, "guardado nas profundezas da alma humana", a que se refere Kant a respeito do esquematismo transcendental dos conceitos quando aplicados à experiência. De fato, afirma Husserl a respeito deste operador, “ (...), a assim chamada consciência interna, é uma verdadeira maravilha tramada de estruturas intencionais as mais finamente tecidas, ainda que profundamente escondidas" (Husserl 3, p. 111). Daremos, certamente, um passo além da descrição fenomenológica se, inspirados na terapia wittgensteiniana, reconhecermos que a própria consciência é também um simples conceito, entre tantos outros, e que seus atos intencionais estão igualmente ligados a convenções lingüísticas criteriais em que, justamente, nos é dada a essência sem mais qualquer halo de mistério, maravilhoso e profundidade. Não apenas no nível perceptivo, como também no nível de seus atos, a consciência se resolve em conteúdos convencionais que podem ser descritos como usos que fazemos da linguagem. A praxis da linguagem, segundo Wittgenstein, permitirá compreender os processos de constituição do sentido da objetividade, guardando, por um lado, a imanência transcendental a ser atribuída ao operador constituinte do sentido - justamente explorada por Husserl, pois abre as portas para uma nova concepção da representação simbólica em que não mais haja o hiato entre as representações e seus conteúdos, ou entre pensamento e extensão e, por outro lado, desfazendo todo o mistério que encerram as estruturas intencionais advindo das profundezas esconsas da subjetividade transcenden- 
tal. Caminhamos, aqui, como diz Wittgenstein, em direção ao solo em que há atrito, ou melhor, o de uma pragmática dos conceitos de inspiração wittgensteiniana.

Para finalizar, poderíamos imaginar um diálogo em que Wittgenstein, provocativamente, indagasse a Husserl se poderia ser concebido, do ponto de vista fenomenológico, um ato de apresentação (Darstellung) de objeto que não correspondesse ipso facto à aplicação de uma significação lingüística, i.e., de uma ligação convencional de sentido. A resposta de Husserl seria, com certeza, negativa, uma vez que cada aspecto do objeto nada mais é do que o conteúdo de um ato intencional, a saber, uma significação, e, não havendo significação sem signo, todo ato de apresentação será um ato lingüístico. Ora, a pergunta simétrica poderia ser endereçada, em tom igualmente provocativo, a Wittgenstein, a saber, se seria possível, do ponto de vista da descrição dos usos das palavras, desvincular o ato lingüístico e a consciência da respectiva significação conceitual. A resposta de Wittgenstein seria igualmente negativa, sem, todavia, a mesma ênfase da negativa husserliana. Porque Wittgenstein acrescentaria - e é nisto, parece-nos, que reside a grande distância entre os dois filósofos, quanto a este ponto - o seguinte esclarecimento: a impossibilidade é aqui apenas gramatical, ou melhor, não é absoluta, dizendo respeito exclusivamente aos usos que fazemos de nossos conceitos, tal como vimos anteriormente no caso da aplicação do conceito de consciência ao estado sonhador e ao vigilante. Isto significa, para Wittgenstein, que seria possível imaginar outras gramáticas relacionando diferentemente os conceitos de consciência e significação, outras formas de constituição da objetividade - aliás, como tanto Wittgenstein quanto Husserl procuram investigar, cada um à sua maneira, a respeito da constituição do sentido relativamente ao universo infantil, aos animais, aos loucos, aos extraterretres... (Husserl 5, textos 11, 14, 27 e anexos X, XI, XIII, XXV e XXVII). A constituição fenomenológica é uma reflexão sobre as formas de integração do diverso à intersubjetividade, enquanto a constituição lingüístico-gramatical é uma reflexão sobre a capacidade expressiva da linguagem. 
Eis, parece-nos, um caminho a ser trilhado para o aprofundamento das relações entre estes dois projetos filosóficos, com inspiração transcendental, de descrição da constituição do sentido da objetividade.

Abstract: This paper applies the therapeutic Wittgensteinian style to the dream's argument in its Cartesian version. In addition it suggests some lines of comparison between the Husserlian project of constitution and the therapeutic Wittgensteinian one.

Key-words: scepticism - dogmatism - phenomenology - therapy - language

\section{Notas}

(1) Permitimo-nos reenviar a três artigos de nossa autoria que apresentam e desenvolvem diferentes aspectos da concepção de uma pragmática filosófica, no sentido aqui evocado: "Por uma pragmática filosófica" em Cadernos de Estudos Lingüísticos, 30, jan./jun. 1996, IEL, Unicamp, Campinas, SP; "Estilo, pragmática, filosofia" em Cadernos de História e Filosofia da Ciência, série 3, V. 5, jan./dez. 1995, CLE, Unicamp, Campinas, SP; "Conseqüências epistemológicas da terapia wittgensteiniana: pragmática filosófica" em Principia, NEL, UFSC, Florianópolis, SC (no prelo). 


\section{Referências Bibliográficas}

1. DESCARTES, R. Méditations. In: CEuvres. Paris, La Pléiade, Gallimard, 1953.

2. Le discours de la méthode. In: Euvres. Paris, La Pléiade, Gallimard, 1953.

3. HUSSERL, E. Erste Philosophie I. Husserliana Bd. VII. Haia, M. Mijhoff, 1956.

4. . Die Krisis der europäischen Wissenschaften und die tranzendentalen Phänomenologie. Husserliana Bd. VI. Haia, M. Mijhoff, 1962.

5. . Zur Phänomenologie der Intersubjektivität, III, I. Kern (ed.). Haia, M. Mijhooff, 1963.

6. . Cartesianische Meditationen, Husserliana Bd. I. Haia, M. Mijhoof, 1973.

7. KANT, I. Crítica da razão pura. Trad. de V. Rohden e U.B. Moosburger, Col. Os Pensadores. São Paulo, Abril, 1983.

8. SPINOSA, B. Éthique. In: Euvres. Trad. de C. Appuhn. Paris, GarnierFlammarion, 1965.

9. WITTGENSTEIN, L. Philosophische Untersuchungen. Oxford, B. Blackwell, 1968.

10. Remarks über die Philosophie der Psychologie. Vs. I-II. Oxford, B. Blackwell, 1980.

11. . Notes sur l'expérience privée et les sense data. Trans-EuropeRepress, Mauvezin, 1982.

12. - Letzte Schriften über die Philosophie der Psychologie. Bd. I. Trans-Europe-Repress, Mauvezin, 1985. 